Elsevier required licence: () 2019

This manuscript version is made available under the CC-BY-NC-ND 4.0 license http://creativecommons.org/licenses/by-nc-nd/4.0/

The definitive publisher version is available online at https://doi.org/10.1016/i.est.2019.100926 


\section{Application of Buoyancy-Power Generator for Compressed Air Energy Storage Using a Fluid-Air Displacement System}

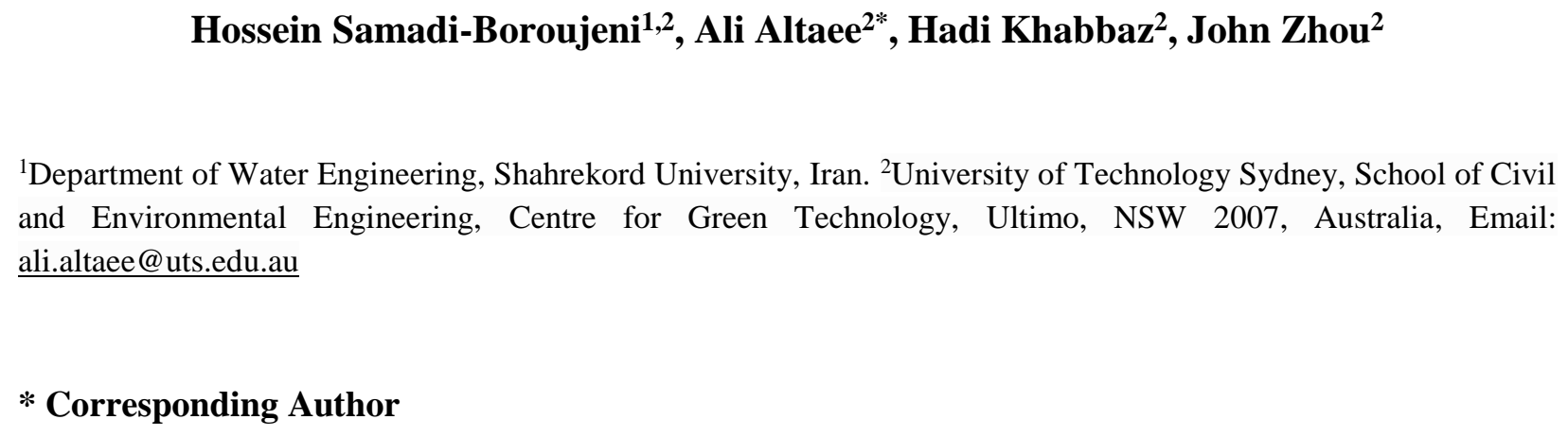

\section{* Corresponding Author}

\section{Abstract}

This study proposes a gravity power generator based on the fluid-air displacement system using Compressed Air Energy Storage from renewable energy sources to increase the solar and wind power system penetration in the power network. A computer model was applied to estimate the performance of the fluid-air displacement system, taking into account the effects of key design and operating parameters. Analysis of the system was performed to calculate the net energy generation as the difference between the energy input and the energy output. Simulation results indicated that the round-trip efficiency of the fluid-air displacement system was between $47 \%$ and $60 \%$, assuming $80 \%$ compressor efficiency. Results also showed that a system generating the maximum energy density should have a speed of cylinders movement of $0.65 \mathrm{~m} / \mathrm{s}$, a cylinder-wall distance of $0.25 \times$ diameter of the cylinder and a gap distance between centers of two tandem cylinders is equal to 1.25. Furthermore, a sensitivity analysis conducted on the main parameters of the system identified that the gap ratio and the buckets moving speed were the highly sensitive parameters to the design and operation of the proposed system. This study also demonstrates the feasibility of using the fluid-displacement system in energy storage from renewable energy technologies.

Key Words: energy storage system, renewable energy, fluid-air displacement system, compressed air energy storage, gravity energy system 


\begin{tabular}{|c|c|c|}
\hline \multicolumn{2}{|c|}{ Nomenclatures } & \multirow{2}{*}{$\begin{array}{l}\text { Unit } \\
\mathrm{N}\end{array}$} \\
\hline$F_{f}$ & total drag force & \\
\hline$C_{d}$ & drag coefficient & -- \\
\hline$U_{o}$ & reference velocity (cylinder moving speed) & $\mathrm{m} / \mathrm{s}$ \\
\hline$A$ & reference area & $\mathrm{m}^{2}$ \\
\hline$D$ & diameter of cylinder & $\mathrm{m}$ \\
\hline$B$ & length of cylinder & $\mathrm{m}$ \\
\hline$G$ & gap distance between the cylinder and wall & $\mathrm{m}$ \\
\hline$L$ & center-to-center spacing of two tandem cylinders & $\mathrm{m}$ \\
\hline$Q_{a}$ & normal demand of air discharge & $\mathrm{m}^{3} / \mathrm{s}$ \\
\hline$u_{i}$ & total velocity & $\mathrm{m} / \mathrm{s}$ \\
\hline $\bar{u}_{i}$ & mean velocity & $\mathrm{m} / \mathrm{s}$ \\
\hline$\dot{u}_{i}$ & fluctuating velocity & $\mathrm{m} / \mathrm{s}$ \\
\hline$\mu_{t}$ & turbulent viscosity & $\mathrm{kg} / \mathrm{m} . \mathrm{s}$ \\
\hline$\delta_{i j}$ & Kroenecker delta function & -- \\
\hline$k$ & turbulent kinetic energy & $\mathrm{m}^{2} / \mathrm{s}^{2}$ \\
\hline$\rho$ & fluid density & $\mathrm{kg} / \mathrm{m}^{3}$ \\
\hline$P_{1}$ & absolute initial atmospheric pressure & $\mathrm{Pa}$ \\
\hline$P_{2}$ & absolute final pressure after compression & $\mathrm{Pa}$ \\
\hline$P_{S}$ & the highest maximum pressure required in compressor & $\mathrm{Pa}$ \\
\hline$\gamma_{f}$ & fluid unit weight & $\mathrm{N} / \mathrm{m}^{3}$ \\
\hline$H$ & the height of the fluid column & $\mathrm{m}$ \\
\hline$P_{w}$ & required compressor power & $\mathrm{W}$ \\
\hline$V$ & volume flow of compressed air at atmospheric pressure & $\mathrm{m}^{3}$ \\
\hline$\gamma$ & ratio of specific heats & -- \\
\hline$N$ & number of compression stages & -- \\
\hline$\eta_{c}$ & overall compressor efficiency & -- \\
\hline$S_{i, j}$ & Sensitivity coefficients & -- \\
\hline$y_{i}(p)$ & model output & -- \\
\hline$R T E$ & round trip efficiency & -- \\
\hline
\end{tabular}

\section{1. Introduction}

2 Energy storage has many benefits in a power network, it is an important component in the energy 3 management system and facilitates to reduce energy wastage and increase the energy utilization

4 efficiency of process systems. Storage of secondary energy forms such as heat and electricity helps

5 to reduce the number of primary energy forms (fossil fuels) consumed to generate them. This is

6 turn not only decreases $\mathrm{CO}_{2}$ and other greenhouse gas emissions together with the associated

7 global warming but also assists to conserve fossil fuels, which are believed to be exhaustible [1].

8 It can also play a crucial role in increasing the penetration of renewable, clean and intermittent

9 energy resources such as wind energy, solar energy, and marine tidal current to the grid as well as

10 help in load shifting [2]. Energy storage improves power system planning, operation and frequency

11 regulation. It facilitates to maintain the energy system stability, improve power quality in micro- 
grid systems as well as match demand with supply [3]. Therefore, there is a need for efficient engineering processes to recover the stored energy and convert into useful work.

Several energy storage technologies have been developed, which are classified into four main groups, including mechanical, electrical, thermal and chemical energy storage. Compressed air energy storage (CAES) and pumped-hydro energy storage are two options of the mechanical energy storage which are the most popular form of energy storage in the worldwide [4-5]. The CAES system operates on a similar principle to pumped hydro, only using air instead of water [5]. Energy savings in the compressed air systems are possible in production and treatment of compressed air, compressed air networks, end-use devices, overall system design and operation. Initially, energy is stored in the form of high-pressure compressed air that will be recovered when the compressed air is released to generate energy. In principles, CAES system has the ability to provide significant energy storage at relatively low costs, fast start-up, and low environmental pollution. Compressed air systems consist of the following key components: intake air filters, interstage coolers, after-coolers, air-dryers, moisture drain traps, receivers, piping network, filters, regulators and lubricators and pneumatic tools and equipment [6]. During the periods of low power demand, the surplus electricity drives a reversible motor/generator unit to run a chain of compressors for injecting air into a storage vessel, which is either an underground cavern or over ground tanks [7]. The underground CAES system requires 10 to $30 \mathrm{MPa}$ to store the compressed gas. Deformation of the rock mass should be insignificant to maintain the integrity of the lining and if the rock is not adequately stiff buckling of steel lining becomes more serious. Furthermore, underground CAES storage system can be designed for large storage capacities and long period discharge times.

He et al. [8] suggested CAES-wind turbine hybrid system in order to reduce the fluctuation in power output. The study presented $2 \mathrm{MW}$ wind turbine coupled with a small-scale CAES system using a dynamic modeling approach. With CAES system, fluctuation in power output was reduced by $38 \%$ and hence extending the stable operation period to 3 hours. A hybrid energy storage system composed of adiabatic CAES and flywheel energy storage system (FESS) was proposed to mitigate fluctuation in the power output of wind turbine [9]. The adiabatic CAES and FESS are able to cope with low and high frequencies in wind power fluctuations, respectively. The study revealed that the wind power with fluctuation between 0 and 49.2 MW was stabilized to a steady power output of $24.18 \mathrm{MW}$ and the loss of wind power was $6.6 \%$ only. In a separate study, Ramadan et al.[10] evaluated the economic feasibility of adding a CAES system to a renewable energy plant. A computer model was developed and simulation results showed that the addition of a CAES system would increase the profitability of the wind energy systems but neither technical evaluation nor process optimization of the CAES system was performed.

Combining CAES and buoyancy energy storage have been addressed in the previous literature. Alami [11] evaluated the CAES system and buoyancy work energy storage (BWES) for off-shore wind power storage. The study identified the main design challenges in the large-scale system to 
be the heat generated due to air compression and the large friction drag affecting the buoys. Unfortunately, the study did not investigate the development and optimization of a buoyancy system to reduce the effect of drag force. Bassett et al. [12] investigated the integration of $1 \mathrm{MWh}$ buoyancy energy storage system with a utility-scale wind turbine. The study calculated the efficiency of a round trip based on drag losses to calculate the efficiency of the buoyancy storage system but did not perform the system design optimization. An underwater buoyancy battery energy storage (BBES) utilizes a simple pulley, reel and float mechanism in energy storage for an indefinite period of time. Maintenance and operation of such an underwater system, however, is rather problematic and would increase the overall cost of the energy generation. A study by Alami [13] proposed a method of energy storage using the work of buoyancy force. The study found that the efficiency of the experimental work exceeded the theoretical estimation due to the material properties of the buoys. There are several advantages offered by the buoyancy storage system such as a compact design, high energy density retrieval, and high efficiencies. Another example of a basic principle of buoyant energy is floating hydraulic energy storage, which is quite similar to that of pumped hydropower storage plants [14].

Research into the uses of buoyancy force for storing energy is still under development. Recently, a buoyancy-powered generator (BPG) has been experimentally applied to the usage of the compressed air energy for electricity production [15]. The basic concept of this method is associated with a plurality of submerged cylinders in a tank filled by a fluid such as water that the cylinders are installed on a rotational sprocket wheel. The cylinders on the vertically upwardly moving side are filled by an air injector and the cylinders on the vertically downwardly moving side are filled by the ambient fluid and different in the cylinder's buoyancy force causes the system to work [16]. One of the most important issues in a buoyancy force system is the accurate prediction of energy losses and drag forces, which is usually done using numerical models. The family of Reynolds-Averaged Navier-Stokes (RANS) models is the most widely used turbulence modeling approach [20].

27 Yet, there are limited studies on the BPG system for power generation to reduce the load on the national grids during peak hours. In this study, the BPG system was evaluated for power generation to increase the penetration level of wind and solar power in the supply network. We assumed that CAES is available to provide compressed air for the operation of the BPG system. BPG system has several advantages such as the capability of scaling-up, constructed from components that can be easily recycled at end-of-life, easy to operate and maintain.

Although battery storage is widely proposed for energy storage from renewable resources, this method causes a major source of environmental pollution. New environmental-friendly technologies such as air-displacement system could replace chemical-based processes to achieve this goal. The system uses buoyancy force for power generation instead of chemical reactions in battery storage technology. The other advantage of the air-displacement system is that it can be 
1 Finally, air-displacement is a modular system, which can be coupled with small and large energy

2 storage systems.

3 This study evaluates a fluid-air system for regenerating of energy stored from renewable resources

4 by an air compressed system. The system is modular and easy to couple with a compressed air

5 technology. Several designs and operating parameters such as system physical dimensions and

6 hydrodynamic properties were investigated in this study and their impact on the system

7 performance is highlighted. The main advantages of the buoyancy-power generator are that

8 minimal water is required in comparison with pumped hydro storage and has insignificant

9 environmental impacts in comparison with batteries and thermal energy storage methods. Water

10 was suggested as the working solution in this study because it is a standard solution and its low

11 dynamic viscosity $\left(0.001 \mathrm{Ns} / \mathrm{m}^{2}\right)$ that reduces the friction force around the moving buckets.

\section{2. Theory and Methods} \\ 2.1. Conceptual CAES/BPG hybrid system}

This study evaluates the buoyancy-powered generator (BPG) with a combination of compressed air energy storage (CASE), briefly called CAES/BPG, like a new electrical energy storage (EES) strategy, in order to increase the penetration level of renewable energy in a power network. The CAES/BPG system includes two main parts, the vessels that function as the buoyancy-powered generator and an air pump/compressor, which converts electricity generated from wind or solar power at an off-peak time to a compressed air for using to operate the buoyancy-powered generator at peak time, as depicted in Fig.1.

1. Charging phase (Off-peak demand)

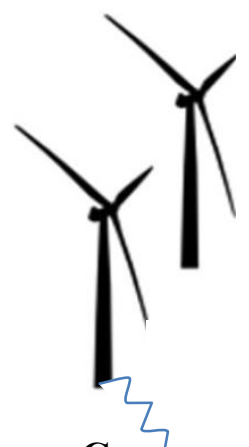

Compressor

\section{Generating phase (Peak demand)}
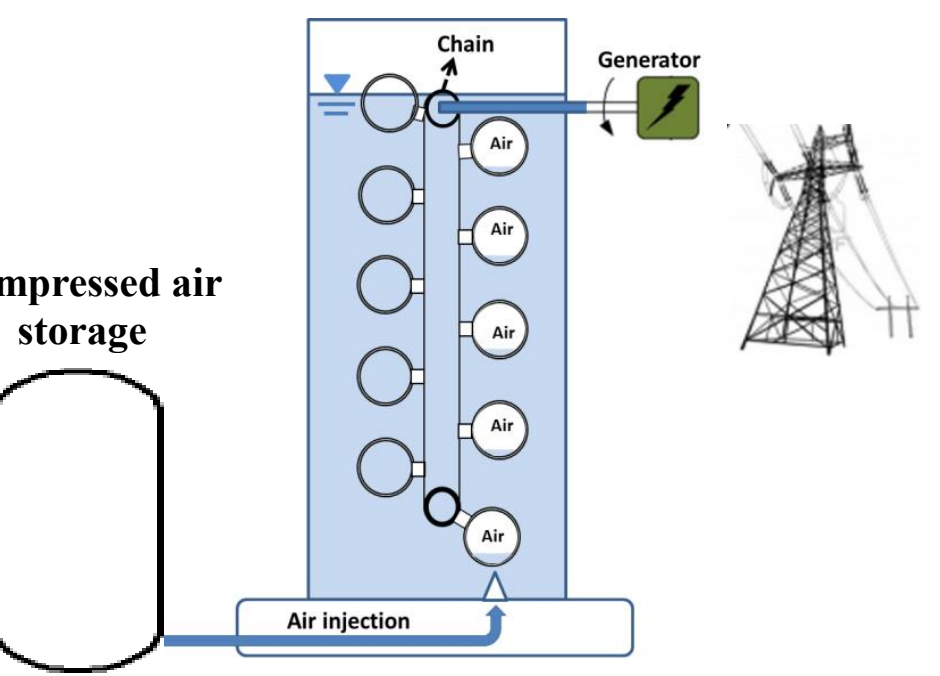

Fig. 1. Basic principle of using CAES/BPG algorithm for power storage 


\subsection{Buoyancy-Power Generator Definition}

2 The present study concentrates on using buoyant energy based on the fluid-air displacement concept as a Buoyancy-Powered Generator (BPG). The overall concept of the generator in its most simple form where lightweight rigid buckets are used to capture the rising air from the air pump as shown in Fig.2. The BPG system can be constructed with two horizontal shafts, two upper sprocket wheels, two lower sprocket wheels and two chain loops submerged in the water which each shaft has one sprocket wheel mounted on it which all components are placed in a water tank. Each of these sprocket wheels engages with a continuous chain loop, which also engages with the sprocket wheel that is positioned vertically above it. These vertical chain loops form belt-style support for a series of identical buckets. On one side, of the vertical belt, the buckets have their open face upwards and on the other side the bucket openings are facing downwards. An air pump is positioned directly underneath the set of buckets, which have the bucket openings facing downwards. The air pump generates an upward-moving stream of air, which collects in the rising buckets, displacing the water filling the bucket. Each bucket with a substantial amount of air in it will create a very significant upward force due to buoyancy, the air being about one thousand times lighter than water. This results in a powerful upward thrust caused by the buoyancy of that bucket, and the thrust causes the bucket to move upwards, rotating both horizontal shafts and bringing another water-filled bucket into position above the air pump. An alternative to air pumps is to use tanks of compressed, non-polluting gas, possibly air. The surface of the liquid, is indicated to illustrate the fact that a bucket, which is in the process of turning over at the top of its orbital motion, is positioned so that one edge of the bucket is above the surface of the water, which allows the air which was trapped inside the bucket to escape into the atmosphere and the water fill the entire bucket causing only a very minor turbulence when doing so. Accordingly, in this system, in the process of the buckets turning over at the top of its orbital motion, when a bucket at the right side of the tank is positioned at the above of the surface of the water the air trapped will escape into the atmosphere and the water will fill the entire bucket at the left of the tank. At this time the bucket positioned at the bottom level will face to the air injection from downward and the air will fill the entire bucket at the right of the tank. Because the bucket movement through the water is relatively slow, a gearing system transfers the rotation torque created to a generator that produces electricity for general purpose uses. Movement of buckets through the water is offset by gearing between the output drive shaft and the generator's input shaft. Therefore, the speed of the buckets can be regulated by the gearing system and the flow rate produced by the air compressor/pump can be used. The power output of the system can be increased by adding more buckets in the vertical chain and increasing the depth of water. Other methods to increase the power output include increasing the volume inside each bucket and/or increasing the flow rate produced by the air pump or used pumps. In this system, different bucket shapes could be used, including flexible membrane types or alternatively, hinged-plate, which have reduced resistance to moving through 
1 the water in the collapsed state in the downward movement. The weight of the buckets is equal on 2 each side of the chain using lightweight buckets to reduce the inertial mass of the moving parts.

3 Several parameters affects the efficiency of the system, such as rotating speed of the chain, the 4 buckets moving speed, size and shape of the buckets, the number of buckets, drag and friction 5 force due to movement of buckets and chain to water body of the tank, discharge of air venting to 6 fill the buckets, the gap ratio and the spacing ratio. These parameters should be taken into account 7 in the design and operation of the system coupling air pump/compressor with the buoyancy8 powered generator composes an energy storage system for wind and solar power. In this study, the 9 analysis of a BPG system has been carried out using various assumptions and simplifications, 10 including:

a) Friction in the sprocket wheel and chain are assumed to be negligible;

b) Drag and friction force due to movement of buckets to water body of the tank can be determined using numerical modeling;

c) The shape of the bucket is a circular cylinder with a diameter $(D)$ of, $0.2 \mathrm{~m}$ and a length (B) of $1 \mathrm{~m}$.

In this research, a gap ratio, $G^{*}=G / D$, between 0.125 and 1 and spacing ratio, $L^{*}=L / D$, between 1.25 and 2 are used in the design of the BPG system, where $G$ is the gap distance between the cylinder and wall and $L$ is the center-to-center spacing of two tandem cylinders.

Furthermore, the buckets moving speed, $U_{o}$, is between 0.1 and $1.3 \mathrm{~m} / \mathrm{s}$. The efficiency of the gearbox may vary in a wide range, depending on the type of gear set [17]. Some types of gear technology such as bevel gears are designed to operate at $98 \%$ efficiency (used on right-angle drives). Spur and helical gears have 97\%-99.5\% efficiency while face gears and beveloids efficiency is about $95 \%$. In this study, the efficiency of the gearbox is assumed $90 \%$. The Reynolds numbers based on the cylinder diameter change from $2 \times 10^{4}$ to $2.6 \times 10^{5}$, which is completely classified in turbulent flow regime. 


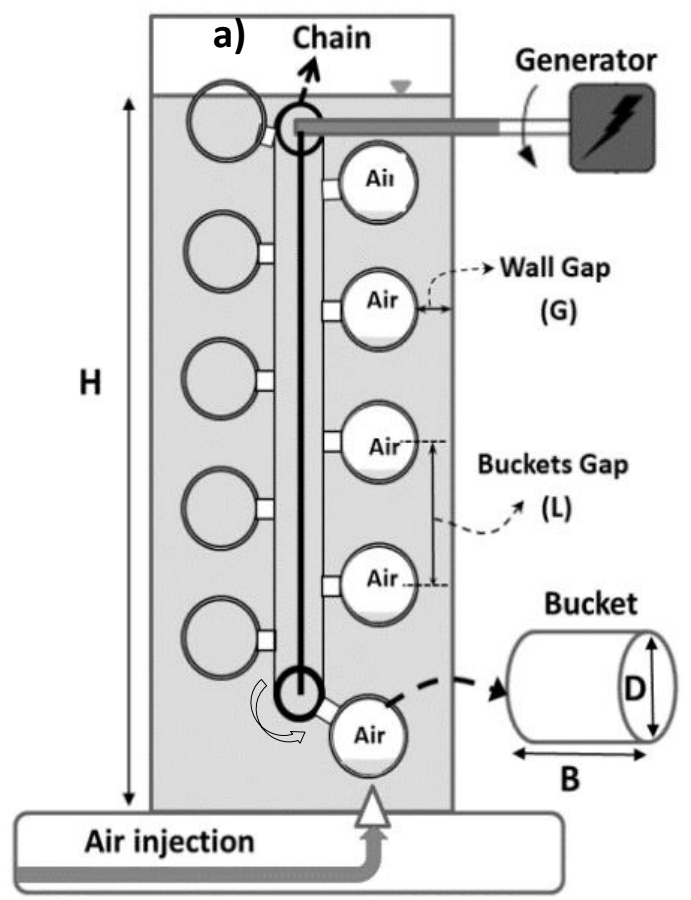

b)

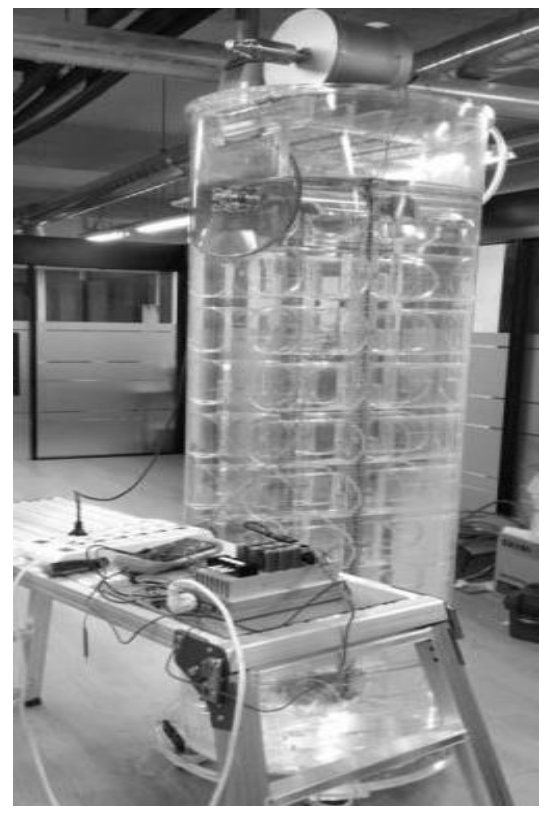

Fig.2.a) Schematic diagram of the buoyancy-power generator tank and b) a photograph of experimental setup by INFINITY SAV TEAM (after [15])

\subsection{Numerical Flow Modeling}

In the BPG system, moving buckets through the tank fluid body causes flow resistance, which should be determined and considered in the planning and design of the system. This resistance refers to the skin friction drag and pressure drag. The first is drag caused by the friction of a fluid against the surface of an object that is moving through it and it is directly proportional to the area of the surface that in contact with the fluid and increases with the square of the velocity. The second is the drag caused by the separation of the boundary layer from a surface and the wake created by that separation, which is primarily dependent upon the shape of the object. The total drag force is obtained by [18]:

$$
F_{f}=0.5 C_{d} \rho A U_{o}^{2}
$$

where $F_{f}$ is the total drag force acting on the object, $C_{d}$ is drag coefficient, $U_{o}$ is a reference velocity and $A$ is a reference area which for a cylinder with diameter $D$ and length $B$, oriented with its axis perpendicular to the direction of flow, the reference area would be $A=D \times B$ ). The total drag force contains both viscous drag (arising from shear stresses exerted by the fluid on the object) and form drag (arising from normal stresses exerted by the fluid on the object). 
$15 \quad \frac{\partial \rho}{\partial t}+\frac{\partial \rho}{\partial x_{i}}\left(\rho u_{i}\right)=0$

$\frac{\partial}{\partial t}\left(\rho u_{i}\right)+\frac{\partial \rho}{\partial x_{i}}\left(\rho u_{i} u_{j}\right)=\frac{\partial \rho}{\partial x_{i}}+\frac{\partial}{\partial x_{j}}\left[\mu\left(\frac{\partial u_{i}}{\partial x_{j}}+\frac{\partial u_{j}}{\partial x_{i}}-\frac{2}{3} \delta_{i j} \frac{\partial u_{i}}{\partial x_{i}}\right)\right]+\frac{\partial}{\partial x_{i}}\left(-\rho \overline{u_{\imath} \dot{u}_{j}}\right)$

18 These above equations (in Cartesian tensor form) are known as RANS equations, and the additional Reynolds stress terms $-\rho \overline{\hat{u}_{\imath} \hat{u}_{J}}$ need to be modeled. The Boussinesq hypothesis is applied to relate the Reynolds stress and the mean velocity:

$21-\rho \overline{u_{\imath} \dot{u}_{j}}=\mu_{t}\left(\frac{\partial u_{i}}{\partial x_{j}}+\frac{\partial u_{j}}{\partial x_{i}}\right)-\frac{2}{3}\left(\rho k+\mu_{t} \frac{\partial u_{k}}{\partial x_{k}}\right) \delta_{i j}$

22 Where $\mathrm{k}$ is the turbulent kinetic energy (TKE), $\rho$ is fluid density, $\mu_{t}$ is turbulent viscosity, and $23 \delta_{i j}$ is Kroenecker delta function.

24 The accuracy of solving RANS equations depends on the turbulence model to determine the 25 Reynolds stress terms. The $k-\varepsilon$ and $k-\omega$ are two such turbulent models, which provide a good compromise between performance and accuracy [22]. The shear-stress transport (SST) $K$ - $\omega$ model 27 was developed by Menter, 1994 [23] to effectively blend the robust and accurate formulation of 28 the $K-\omega$ model in the near-wall region with the free-stream independence of the $k$ - $\varepsilon$ model in the far-field. The $K-\omega$ SST model is more accurate and reliable than the standard $k-\varepsilon$ model for a wider class of flows such as adverse pressure gradient flows, airfoils, transonic shock waves [23]. 
ANSYS Fluent software solves the RANs equations based on the finite volume method [24]. This software is also capable to solve the Reynolds stress terms using a wide range of turbulent models, such as $k-\varepsilon$ Standard, $k-\varepsilon$ RNG, $k-\omega$ SST, $k-\omega$ Standard, Transition SST and Spalart-Allmaras which are applied in this study as the common models [25,21]. Since none of the turbulent models is universal, a series of tests were performed to check which model is the most effective to capture the flow behavior. The results for the case of $G^{*}=0.5$ and $U_{o}=1.1 \mathrm{~m} / \mathrm{s}$, as illustrated in Fig.3, show that difference among the drag coefficients, obtained from different turbulent models, are not significant at $95 \%$ confidence interval. For selecting the appropriate turbulent model, convergence criterion was used and variation of the residual values versus the number of iteration for effective parameters such as continuity, $Y$-velocity, $\omega, \varepsilon$ and $K$ was plotted in Figs. 4.a to 4.d. These figures show that the $k-\omega$ SST turbulence model is the most appropriate model according to the amount of the residual of continuity, $Y$-velocity, $\omega, \varepsilon$ and $K$ parameters. It is in a good agreement with Patel [25], Young and Ooi [26], Coughtrie et al. [27], Ducrocq et al. [28], Rahimzadeh et al.[29] and Dogan et al. [30] that demonstrated $k-\omega$ SST model can accurately and reliably predict the drag coefficient in a wide class of flows around cylinders. A Numerical study of flow past a circular cylinder using different turbulence formulations showed that the $k-\omega$ SST model predicts similar vortex shedding phenomenon to that for LES model [31]. Therefore, the $k-\omega$ SST turbulence model was applied to calculate the drag force for all cases of the BGP vessel arrangements. A skewness mesh less than 0.5 was considered in this study and different mesh sizes, from coarse to dense, were generated to ensure that the simulation results were sufficiently grid-independent. As shown in Fig.5, the drag coefficient, $C D$, became stable and remained nearly unchanged when the number of mesh elements was higher than 20 nodes per $\mathrm{cm}^{2}$. Considering the computational efficiency, a quadrilateral mesh size between $3 \times 10^{-5} \mathrm{~m}$ and $3 \times 10^{-3} \mathrm{~m}$, which resulted in minimum nodes number of 20 nodes per $\mathrm{cm}^{2}$, was used for further simulation. Furthermore, the input parameters such as pressure, density and viscosity were considered at sea level conditions. The input velocity at the inlet was set for the scenarios studied from $0.1 \mathrm{~m} / \mathrm{s}$ to $1.3 \mathrm{~m} / \mathrm{s}$, which results in Reynolds number from $2 \times 10^{4}$ to $2.6 \times 10^{5}$. The top and bottom walls of the rectangular tank domain were assigned as the inlet and the outlet and also the left and right sides of the tank are defined as moving walls parallel to the inlet velocity direction with the same velocity. The turbulence intensity was set at $5 \%$, according to the low-intensity range reported in reference [18]. In order to avoid calculation errors, double precision was set and in order to maintain accuracy second-order discretization was set for pressure, momentum and viscous terms and the convergence criterion was set at $1 \times 10^{-5}$. Fig. 6 shows velocity countors pattern and boundary condition definition in case of $G^{*}=0.25$, $L^{*}=1.25$ and $U o=0.5 \mathrm{~m} / \mathrm{s}$ using $k-\omega$ SST model. 


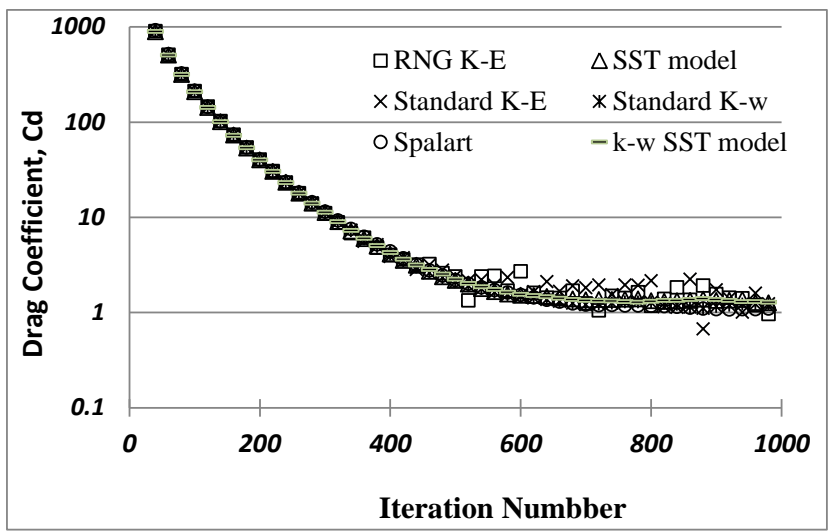

Fig.3 Drag Coefficient variation versus iteration number in case of

$$
G^{*}=0.5, L^{*}=1.25 \text { and } U_{o}=1.1 \mathrm{~m} / \mathrm{s}
$$

a)

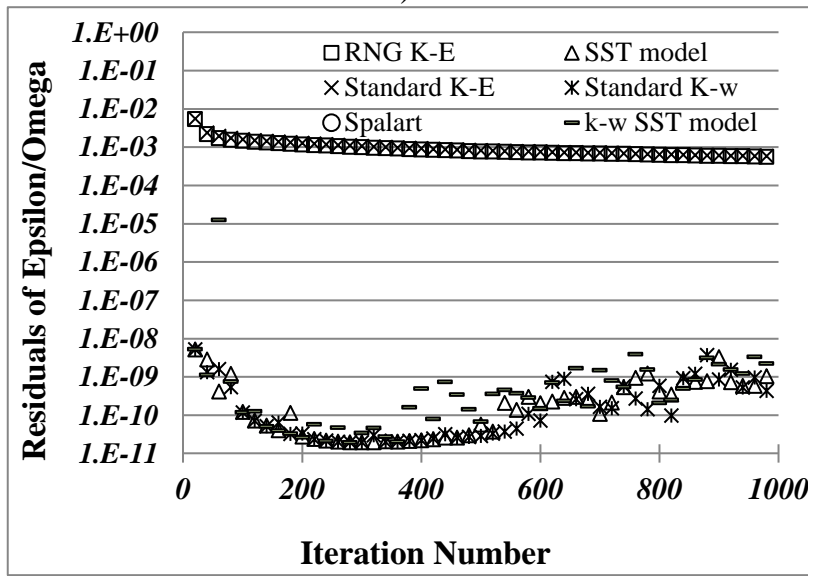

c)

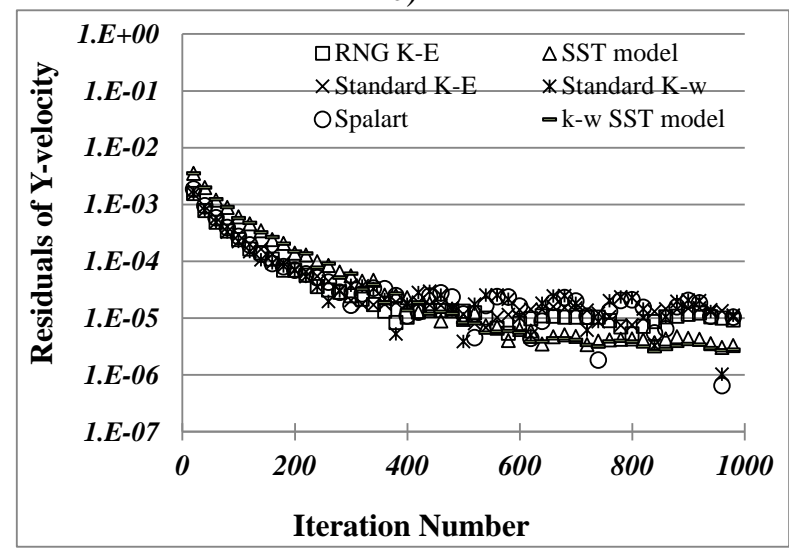

b)

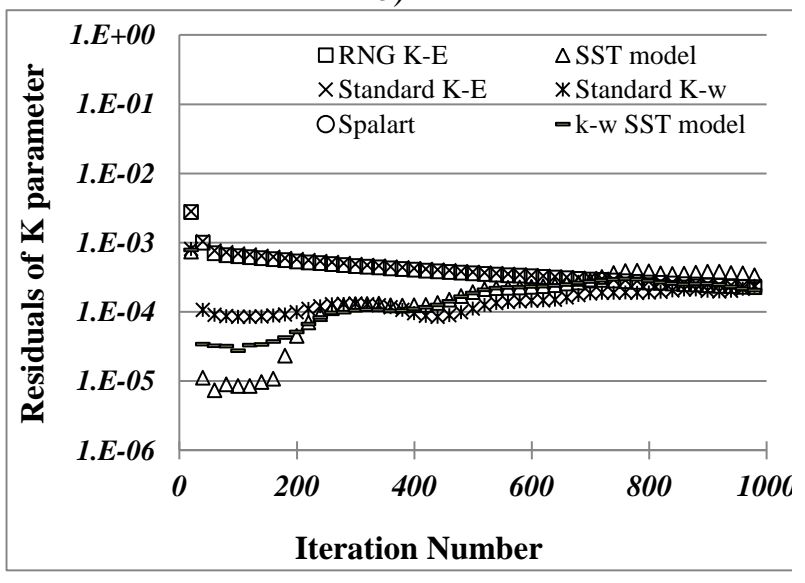

d)

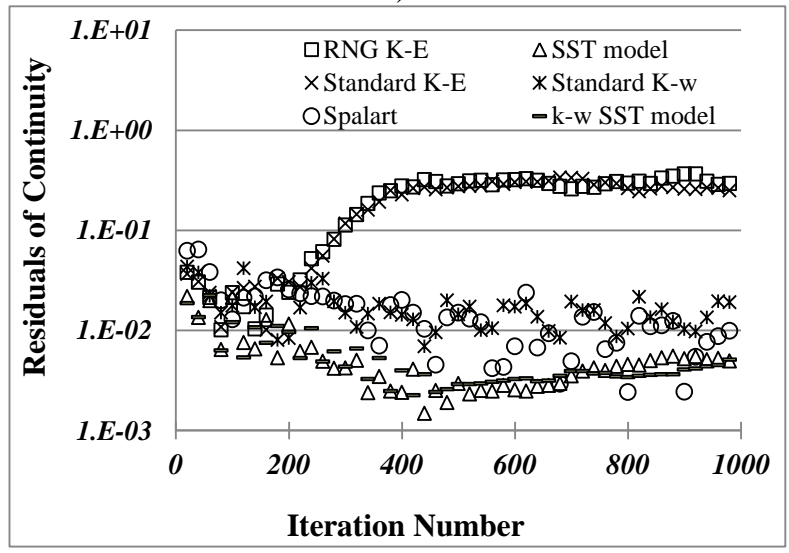

Fig.4 Residual variations versus iteration number in case of $G^{*}=0.5, L^{*}=1.25$ and $U_{o}=1.1 \mathrm{~m} / \mathrm{s}$; a) $\varepsilon$ or $\omega$ parameter, b) $K$ parameter, c) $Y$-velocity, d) Continuity parameter 


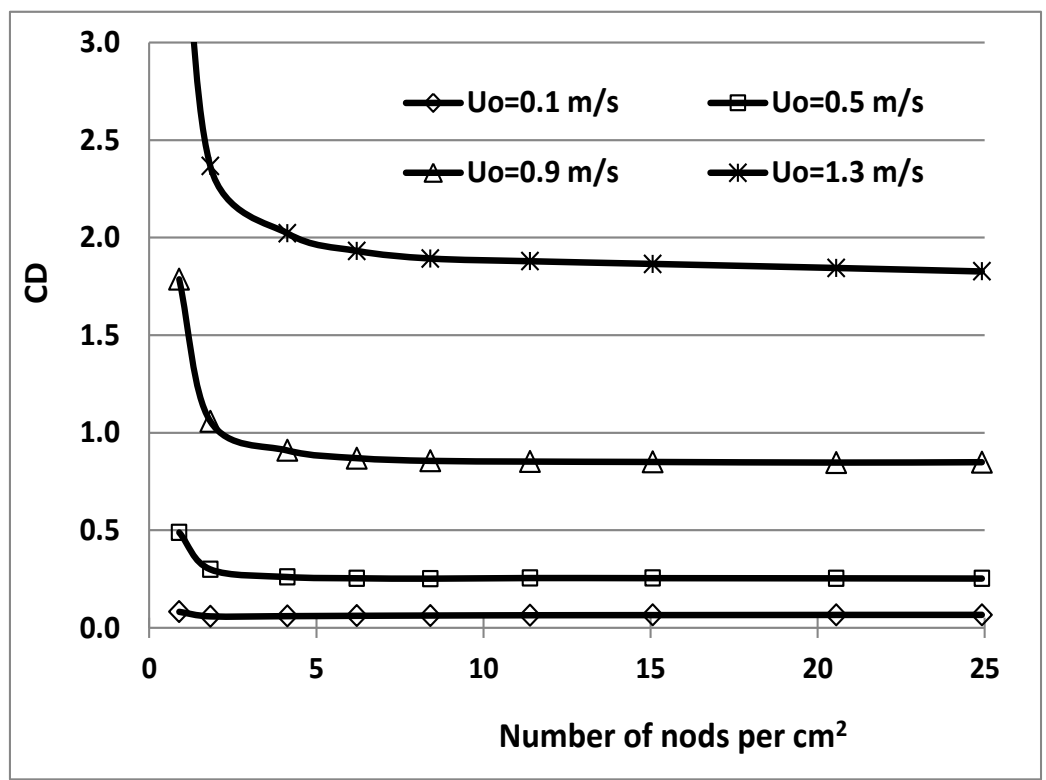

Fig. 5 Validation of mesh independency, drag coefficient vs nodes number per domain area for different buckets moving speed

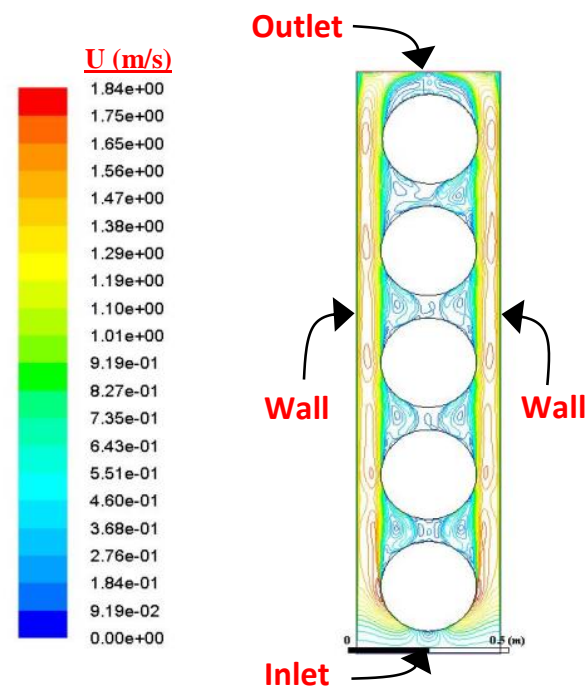

Fig. 6. Velosity countors and boundary condition defination in case of $G^{*}=0.25, L^{*}=1.25$ and $U o=0.5 \mathrm{~m} / \mathrm{s}$. 


\subsection{Air Compressor Considerations}

2 There are different types of air compressors, but reciprocating compressors as positive 3 displacement compressors, are the most widely used type for air compression. This type of 4 compressor is characterized by a flow output that remains nearly constant over a range of discharge 5 pressures. Reciprocating compressors are used in the capacity range of 0.014 to $2.78 \mathrm{~m}^{3} / \mathrm{s}$, with 6 discharge pressure up to 700 bars [32].

7 In order to estimate the capacity of the compressor, the normal demand of air discharge should be 8 determined. The normal demand for air discharge $\left(Q_{a}\right.$, in $\mathrm{m}^{3} / \mathrm{s}$, at $0^{\circ} \mathrm{C}$ and $\left.1 \mathrm{bar}\right)$, based on the 9 mass conservation law, is calculated using the following relationship in the SI system of units:

$11 \quad Q_{a}=\frac{V_{a}}{t} \quad, \quad V_{a}=B \cdot \frac{\pi D^{2}}{4} \quad, \quad t=\frac{L}{U_{o}}$

where $V_{a}$ is the volume of air for filling a bucket, $\mathrm{t}$ is time duration for filling the bucket by air, $D$ is the cylindrical bucket diameter, $B$ is the cylindrical bucket length, $L$ is the gap distance between two tandem cylindrical buckets centerline and $U_{o}$ is the cylindrical buckets moving speed. In this study, the amount of $Q_{a}$ varies from a minimum value of $0.01256 \mathrm{~m}^{3} / \mathrm{s}$ (in case of $G^{*}=$ 0.25 and $U_{o}=0.1 \mathrm{~m} / \mathrm{s}$ ), up to a maximum value of $0.0816 \mathrm{~m}^{3} / \mathrm{s}$ (in case of $G^{*}=1.5$ and $U_{o}=1.3$ $\mathrm{m} / \mathrm{s})$.

The air compressor outlet pressure is another parameter used for assessing the compressor capacity. Minimum pressure outlet of the compressor should not be less than a hydrostatic pressure at the bottom of the buoyancy-power generator tank, where a nozzle delivers air to fill the cylindrical buckets. Moreover, the compressor design pressure should be the minimum pressure plus the required pressure to storage secondary energy receiving from wind or/and solar power and it depends on secondary power capacity, time of off-peak energy when the compressor consumes energy and volume of compressors storage vessel according to the following equation:

Where, $P_{2}$ is the absolute final pressure after compression, which is the highest maximum pressure required in the compressor, $P_{S}$ is the required absolute pressure in compressors storage vessel for storing secondary energy, $\gamma_{f}$ is the fluid unit weight and $H$ is the height of the fluid column in the buoyancy-power generator tank. 
1 Finally, compressor power required to compress of free air (atmospheric pressure) to final pressure

2 for an adiabatic condition (process without transfer of heat) can be expressed as following [18].

$4 \quad P_{w}=\frac{N \cdot V \cdot \gamma \cdot P_{1}}{(\gamma-1) \cdot \eta_{c}}\left[\left(\frac{P_{2}}{P_{1}}\right)^{\left(\frac{K-1}{N \cdot K}\right)}-1\right]$

6 where $P_{w}$ is the required compressor power (watts); $V$ is the volume flow of compressed air at 7 atmospheric pressure $\left(\mathrm{m}^{3} / \mathrm{s}\right) ; P_{1}$ is the absolute initial atmospheric pressure $(101325 \mathrm{~Pa}$ at sea

8 level); $P_{2}$ is the absolute final pressure after compression ( $\mathrm{Pa}$ ) as formulized in equation $7 ; \gamma$ is the 9 ratio of specific heats $\left(1.4\right.$ for air at $20^{\circ} \mathrm{C}$ ); $\mathrm{N}$ is number of compression stages and $\eta_{c}$ is overall 10 compressor efficiency includes motor and blower efficiencies.

11 Compressor efficiencies vary with compressor type, size, and throughput. They can only be exactly 12 determined by a compressor test, although compressor manufacturers can usually provide good 13 estimates [33]. For planning purposes, Campbell [34] suggests the values for the overall 14 efficiencies of compressor include gas friction within the compressor, the mechanical losses 15 (bearings, seals, gear-box, etc.), and gear-box losses as in Table 1 [35]. Adding 3-4 \% efficiency 16 (mechanical losses) to the overall efficiencies in Table 1, will generally give a good estimate of 17 the thermodynamic efficiency. It should be also noted that if the compressor system to be made 18 and operated under poor management, leaks may waste up to 50\% of the compressed air produced 19 by the compressor. In this work according to table 1 , an efficiency of $80 \%$ for a compressor can 20 be assumed.

21

22

Table 1. Overall compressor efficiencies [35]

\begin{tabular}{|c|c|c|}
\hline Row & Compressor Type & Efficiency, $\eta$ \\
\hline 1 & Centrifugal & $0.70-0.85$ \\
\hline 2 & High Speed Reciprocating & $0.72-0.85$ \\
\hline 3 & Low Speed Reciprocating & $0.75-0.90$ \\
\hline 4 & Rotary Screw & $0.65-0.75$ \\
\hline
\end{tabular}

\section{3. Results and Discussion}

25 3.1. Evaluation of the Buoyancy-Power Generation 
1 The buoyancy power generation in the CAES/BPG system is defined as net buoyancy force acting 2 on bucket movement multiple by the buckets moving speed. The net buoyancy force depends on 3 the air-filled buckets submerged buoyancy force and the system losses which include the drag

4 force effect, compressor losses, gearbox friction and wasting air from the buckets.

5 The total drag force is determined based on the numerical modeling results, as described in the 6 previous section. Fig.7 shows the variation of drag force versus the buckets moving speed for 7 different $G^{*}$ and $L^{*}$. Results show that the total drag force is increased with decreased $G^{*}$ and 8 Fig.7.b shows that inverse relationship with $L^{*}$ (Fig.7.a). That is because of the gap distance effects 9 on the pressure distribution at the tandem cylinders, flow pattern and turbulence generation. Also, 10 the results show that the total drag force in $G^{*}=0.125$ is significantly much higher than that of $G^{*} \geq 0.25$, because of the wall effects and blockage of the flow around the cylinders. For $G^{*}>0.5$ there is not observed a significant difference in the amount of drag force. Experimental study of flow around two tandem circular cylinders conducted by Wang et al. [19] showed that when $G^{*}$ increases to 0.6, the wall effects exist at a small degree and become almost negligible, such that the flow is similar to a free-standing case, at $G^{*}=1.4$. This result is in agreement with the present work findings.

Other losses due to compressor and gearbox can be estimated based on their efficiencies. By assuming the typical technologies an efficiency of $80 \%$ for the compressor and an efficiency of $90 \%$ for the gearbox are considered. Besides, in order to consider the effects of wasting air from the buckets, it is assumed that $10 \%$ of air injection into the tank is not trapped into the buckets. Because of the uncertainty of these assumptions, a sensitivity analysis has been carried out in this work.

a)

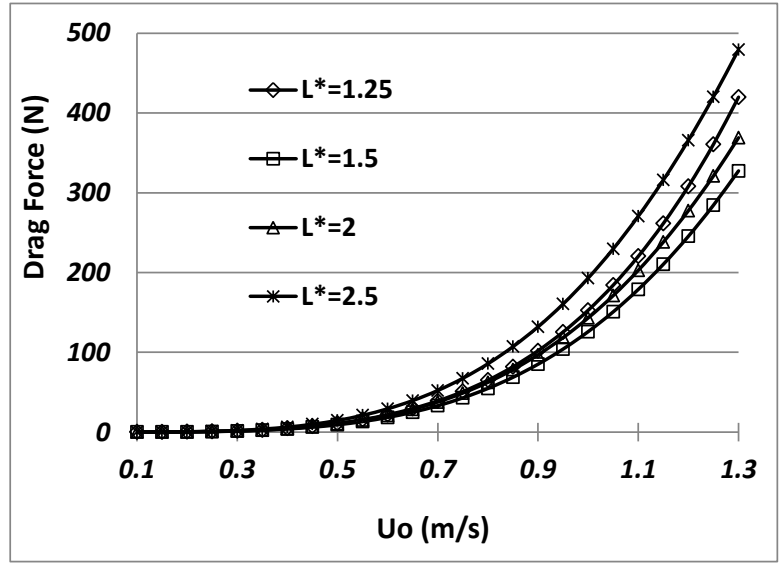

b)

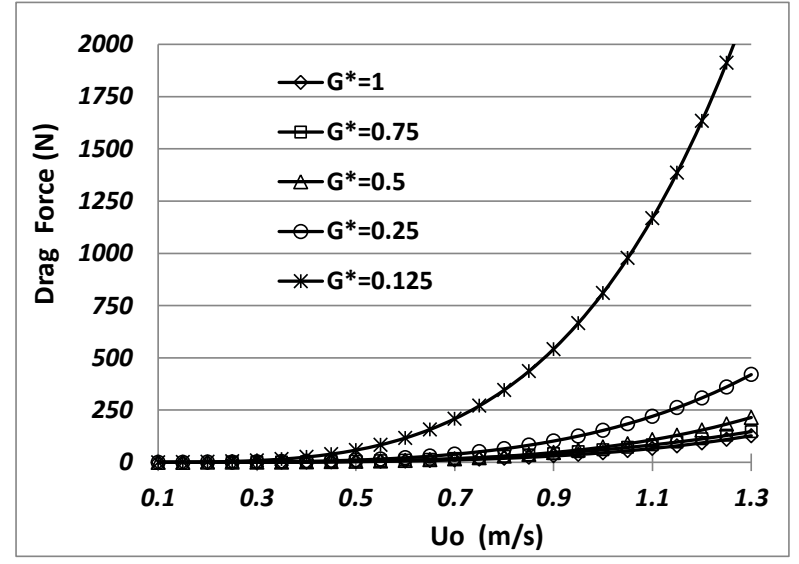

Fig.7 Drag force versus the buckets moving speed; a) for different $L^{*}$ and $G^{*}=0.25$; b) for different $G^{*}$ and $L^{*}=1.25$ 
1 In order to assess the portion of the buoyancy force, which is lost, the ratio of drag force to the 2 buoyancy force is calculated and its variations versus the buckets moving speed are drawn in Fig. 38 , for different $G^{*}$ an $L^{*}$. The results show that in case of $G^{*}=0.125$, if the buckets moving speed 4 reaches up to $0.64 \mathrm{~m} / \mathrm{s}$ the ratio of drag force to the buoyancy force would reach up to $100 \%$. It 5 means that the buoyancy force will be completely consumed by the system losses, therefore in 6 design and operating the system, the buckets moving speed must be considered less than a 7 maximum rate. From Fig. 8.a, the maximum speed of the buckets moving is obtained 1.35, 1.3, $8 \quad 1.19$ and $1 \mathrm{~m} / \mathrm{s}$ for $G^{*}$ equal to $1,0.75,0.5$ and 0.25 , respectively. As shown in Fig. 8.b, the 9 corresponding values for $L^{*}$ are equal to $1.25,1.5,2$ and 2.5 are $0.99,1.05,1.01$ and $0.93 \mathrm{~m} / \mathrm{s}$, 10 respectively.

a)

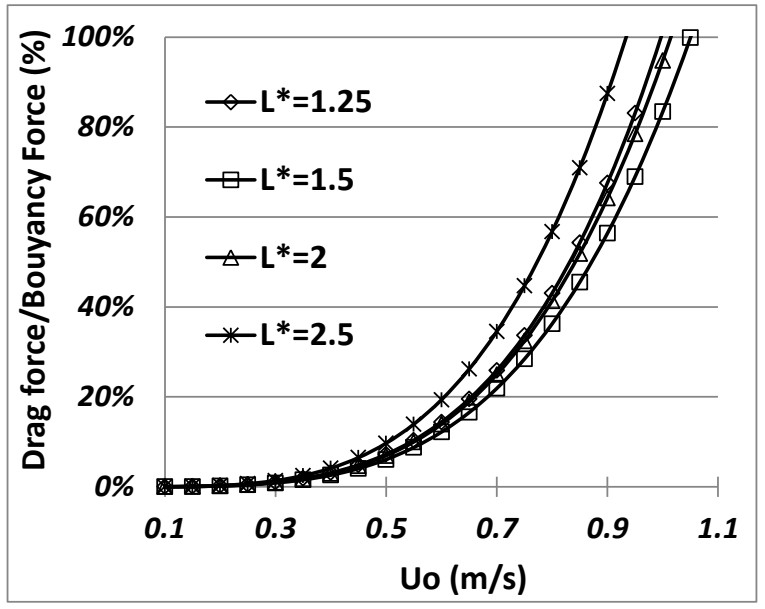

b)

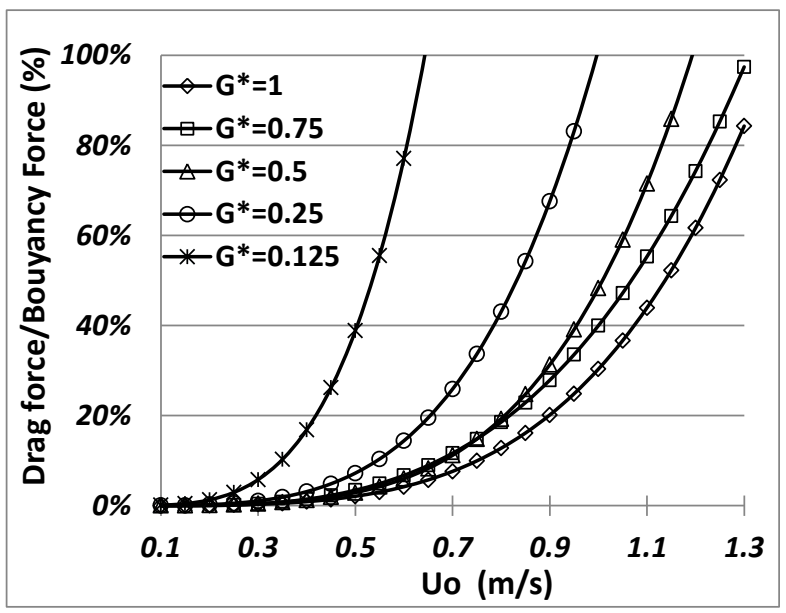

Fig. 8 Drag force per buoyancy force versus the buckets moving speed; a) for different $L^{*}$ and $G^{*}=0.25$; b) for different $G^{*}$ and $L^{*}=1.25$.

The net buoyancy power density $\left(P_{b-N e t}\right)$ was calculated as the net buoyancy force $\left(F_{b-n e t}\right)$ per cubic meter volume of the tank, by using the following relationship:

$P_{b-N e t}=\frac{F_{b-n e t} \times U_{o}}{V_{t}}$

Where $V_{t}$ is the total volume of the tank, and $F_{b-n e t}$ is the net buoyancy force of the buckets filled by air. Practically, buoyance force is calculated as $F_{b}=V_{s} \times \rho_{f} \times g\left(F_{b}\right.$ is the buoyancy force, $V s$ is the submerged volume of the object, $\rho_{f}$ is the density of the fluid, and $g$ is the gravity force. The variation of the net buoyancy power density versus $U_{o}$, as illustrated in Fig. 9, show that the net buoyancy power density reaches a maximum value at the buckets moving speed of $0.65 \mathrm{~m} / \mathrm{s}$, if $L^{*}$ and $G^{*}$ are selected as 0.25 and 1.25 , respectively. This emphasizes the significance of the drag force effects on the performance of the BPG system. Fig. 10 shows the 
optimum speed of the moving buckets versus the gap and the spacing ratios based on the maximized net buoyancy power density. The results show that the optimum speed of the moving buckets increases by increasing $G^{*}$ while the optimum speed slightly decreases with increasing $L^{*}$. Fig. 10 also shows that the optimum speed is more sensitive to the gap ratios than to the spacing ratio.

a)

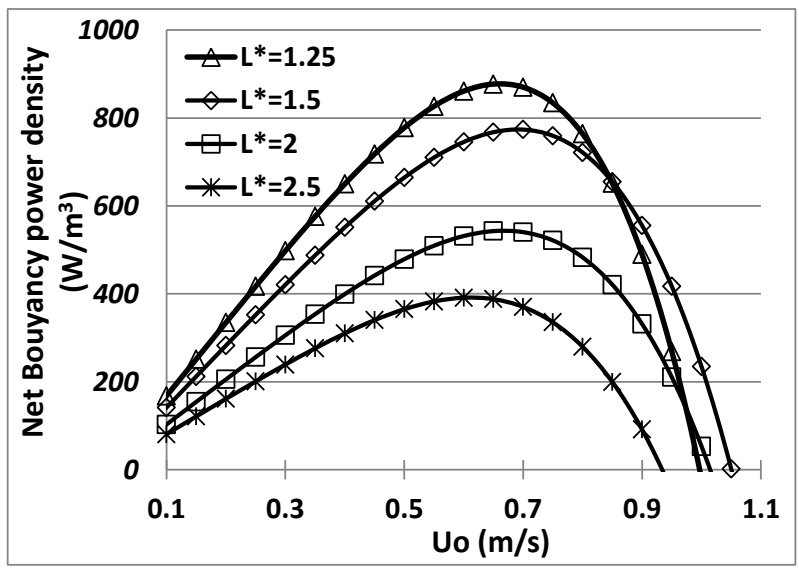

b)

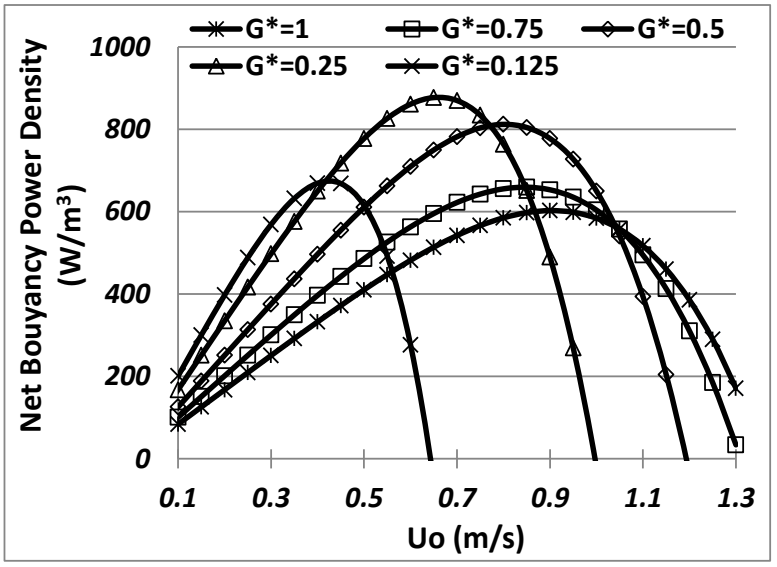

Fig. 9 Net buoyancy power density versus the buckets moving speed, a) for different $L^{*}$ and $G^{*}=0.25$, b) for different $G^{*}$ and $L^{*}=1.25$.

a)

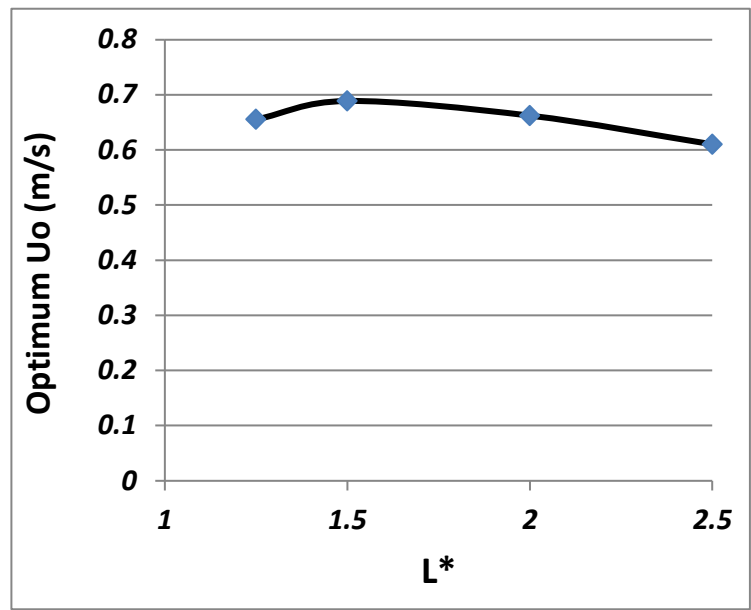

b)

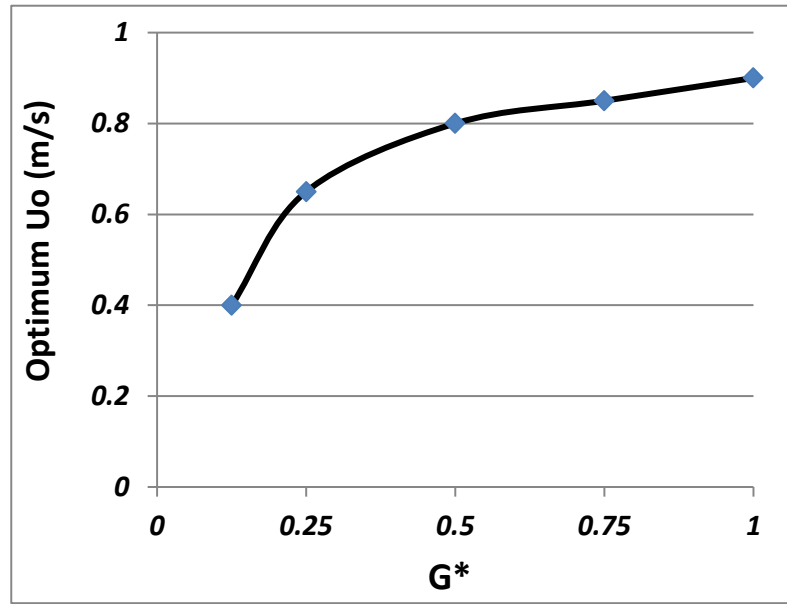

Fig. 10 The optimum speed of the buckets moving versus the gap ratios and the spacing ratios, a) for different $L^{*}$ and $G^{*}=0.25$; b) for different $G^{*}$ and $L^{*}=1.25$. 


\subsection{Evaluation of the Net Energy Generation}

2 Energy consumption, called energy input, is compressor's energy required for providing pressured 3 air to operate the fluid-air displacement system and also recovery of the other system energy losses.

4 It is determined according to the power required calculated by Equation 8, multiple by the time 5 duration. It can be converted to the energy density by considering the volume of the tank. In 6 addition, energy production, called energy output, is determined according to the net buoyancy 7 power density multiplied by the elapsed time and converted to the energy density by considering 8 the volume of the tank. For one hour time period, Fig. 11 shows the variation of energy density 9 consumption and production versus the buckets moving system, in case of $G^{*}=0.25$ and $L^{*}=1.25$. 10 The energy density production versus the buckets moving speed is drawn in Fig. 11. The results 11 show that the energy output is less than energy input because of the effects of the compressor 12 friction, the gearbox losses, wasting of air from the buckets and resistance of the buckets movement trough the fluid. The difference between energy input and energy output has an increasing trend by increased the buckets moving speed so that the total energy input would be completely consumed by the losses in the speed up to $1 \mathrm{~m} / \mathrm{s}$. The maximum value of the energy density output occurred at the buckets moving speed of $0.65 \mathrm{~m} / \mathrm{s}$, which indicates that lower and higher speeds may negatively affect the performance of the BPG system. Practically, bucket moving speed needs to be optimized for the system to maximize the power output.

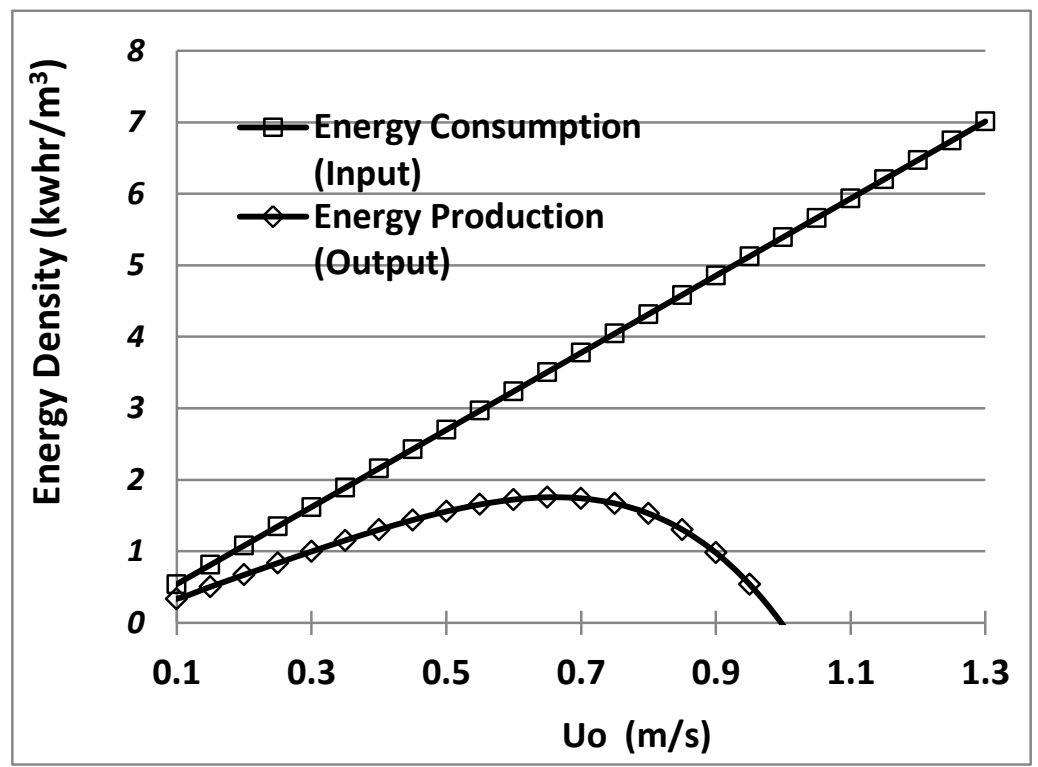

Fig. 11 Energy density production and consumption versus the buckets moving speed in case of $G^{*}=0.25$ and $L^{*}=1.25$.

\subsection{Round Trip Efficiency and Potential Application}


Round trip efficiency $(R T E)$ is defined as the ratio of total energy storage system output (discharge) divided by total energy input (charge) as measured at the interconnection point. Fig. 12 shows the round trip efficiency versus the buckets moving speed with different gap ratios. It indicates that increasing of the buckets moving speed causes the efficiency to decrease because of increasing the system energy losses. For the bucket moving speed of $0.65 \mathrm{~m} / \mathrm{s}$ and $G^{*}=0.25$ and $L^{*}=1.25$, which the maximum energy density output is occurred at, the system efficiency is obtained $50.1 \%$. By increasing $G^{*}$, the efficiency will be increased so that the efficiency will be obtained up to $60 \%$ for $G^{*}=1$. Also by reducing the bucket moving speed up to $0.25 \mathrm{~m} / \mathrm{s}$, the achieved efficiency would reach $62.2 \%$. It should be noted that at this rate, the energy density output will not reach a maximum value.

In order to indicate energy efficiencies in the process of electricity consumption, energy generation and also energy losses during its transmission, a Sankey diagram has been provided as shown in Fig.13. In this figure, the wasting air refers to the air discharge from the compressed air storage that would not trap into the buckets and it is assumed to be $10 \%$ in this study. It is shown that the round trip efficiency of the proposed method, obtained to be between 47 and $60 \%$ for the buckets moving speed of $0.65 \mathrm{~m} / \mathrm{s}$, can be considered as a comparable method with other energy storage technologies, such as Hydro, Flywheels, Batteries, Electrothermal (ETES) and Compressed Air (CAES) which have the round trip efficiency of 65-80\%, 80-90\%, 75-90\%, 65-75\% and 65-75\%, respectively [36, 37]. There are several technologies available for energy storage with different operating capacities [Fig. 14]. Out of these technologies, the method used in this study, BPG/CAES, has great potential for implementation as storage systems of small to average capacities between $1 \mathrm{~kW}$ to $1 \mathrm{MW}$. BPG/CAES system is a fast response system, which does not need expensive components such as turbines, heat exchanger, chemical reactions, or expensive structures and can be retrofitted with an existing CAES system. Furthermore, it can be built from inexpensive parts that can be, easily, recycled at the end of the service life. As an application example, according to the obtained results in this study, 5 cylindrical buckets on each side of the tank with a diameter of $1.1 \mathrm{~m}$ and a length of $4 \mathrm{~m}$ are required to generate $100 \mathrm{~kW}$. According to these assumptions, the BPG tank should be $7.5 \mathrm{~m}$ height and $3.3 \times 4 \mathrm{~m}^{2}$ area. Air discharge consumption would also be about $2 \mathrm{~m}^{3} / \mathrm{s}$ in normal conditions ${ }^{1}$. 
a)

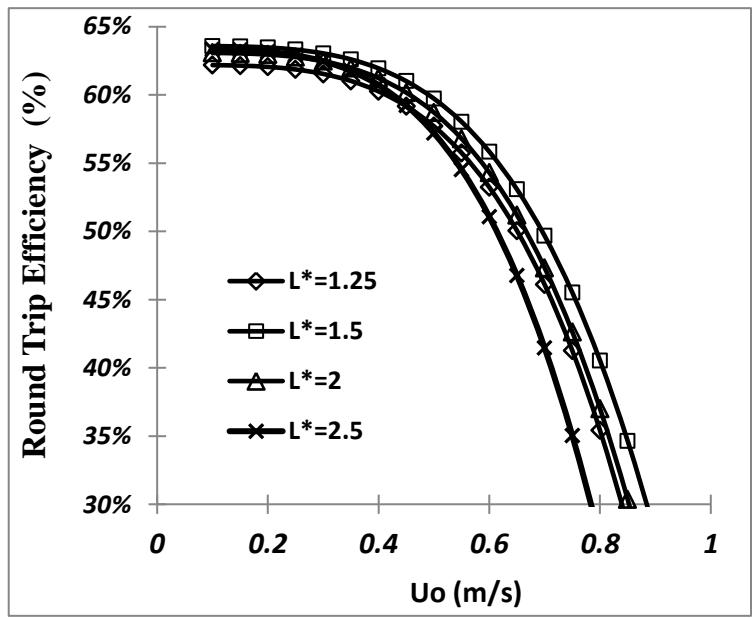

b)

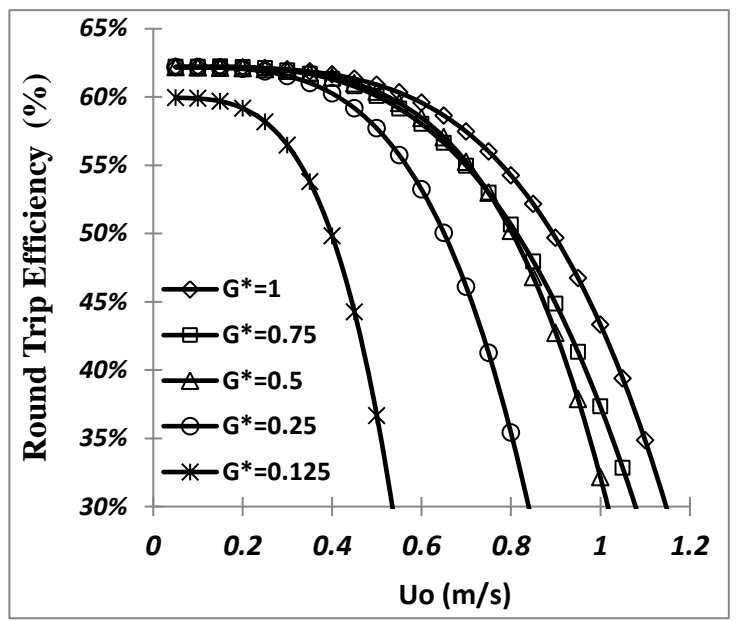

Fig.12. The round trip efficiency of energy storage versus the buckets moving speed, a) for different $L^{*}$ and $G^{*}=0.25 ;$ b) for different $G^{*}$ and $L^{*}=1.25$.

2

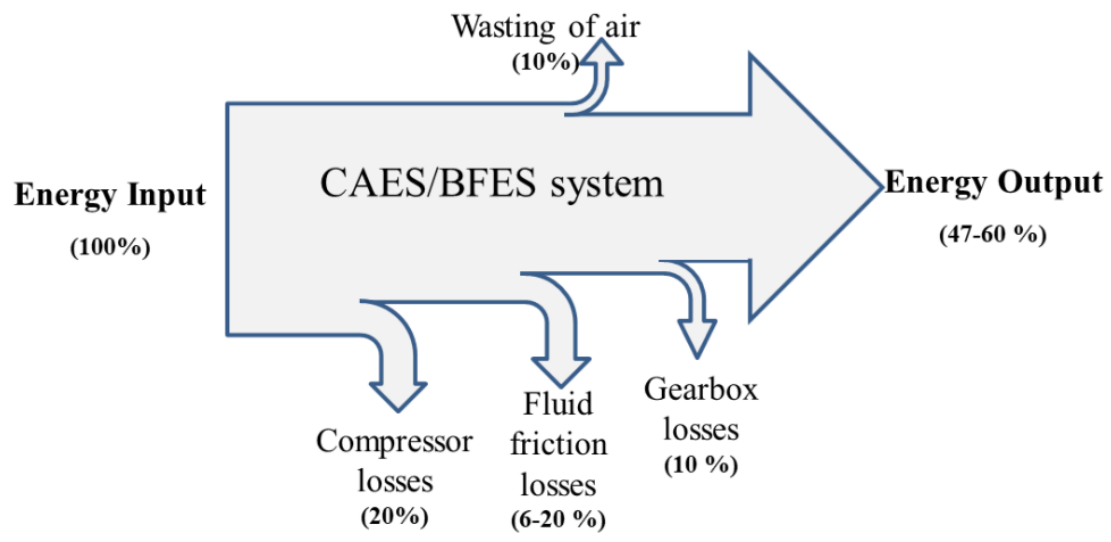

Fig.13 Sankey diagram for the CAES/BPG system 
$9 \quad S_{i, j}=\left.\frac{\partial y_{i}(p)}{\partial p_{j}}\right|_{p=p^{*}}$

If not analytically available, $S_{i, j}$ can in the simplest case be approximated via finite differences,

$14 S_{i, j} \approx \frac{y_{i}\left(p^{*}+\Delta p_{j}\right)-y_{i}\left(p^{*}\right)}{\Delta p_{j}}$

In this study, the sensitivity analysis parameters were selected including the efficiency of compressor, the efficiency of gearbox, air wasting from the buckets, the buckets moving speed $\left(U_{o}\right)$, the Gap ratio $\left(G^{*}\right)$ and the Spacing ratio $\left(L^{*}\right)$ and the effects of changing of these parameters on the changes in round trip efficiency $(R T E)$ was evaluated. Table 3 shows the reference value of the parameters in the case of $G^{*}=0.25, L^{*}=1.25$ and $U_{o}=0.65$ which provides maximum energy density 
1 production. A spider diagram used to compare relative changes in model output to relative changes

2 in the parameter values can reveal sensitivities for each parameter [38]. The legs of the spider

3 represent the extent and direction of the effects of changing parameter values. Obtained results, as

4 shown in Fig.15, indicates the sensitivity analysis for the round trip efficiency $(R T E)$. The gap ratio

5 parameter has the highest effect on the resulting $R T E$; if the gap ratio varies by $10 \%$, the $R T E$

6 changes by $15.6 \%$. Other main influencing factors are the buckets moving speed and efficiency of

7 air compressor and gearbox, of which variation by $10.8 \%$ results in a change in RTE of about $10 \%$.

8 The impacts of the spacing ratio and air wasting from the buckets are lower than other parameters.

9 This means that the gap ratio and the buckets moving speed are highly sensitive in the design and

10 operation of the proposed system. Future work should focus on building a laboratory size air-

11 displacement system for power generation and model validation using experimental data. Research should

12 also focus on the design of a system that uses recyclable materials that reduce environmental pollution upon

13 disposal. A thermodynamic analysis of the experimental system is required to give more information about

14 the energy efficiency of the air-displacement system.

Table 3 The base values of the sensitivity analysis parameters

\begin{tabular}{|c|c|c|c|c|c|c|}
\hline $\begin{array}{c}\text { Sensitivity } \\
\text { Analysis } \\
\text { Parameters }\end{array}$ & $\begin{array}{c}\text { Air } \\
\text { compressor } \\
\text { efficiency }\end{array}$ & $\begin{array}{c}\text { Air } \\
\text { wasting } \\
\text { from the } \\
\text { buckets }\end{array}$ & $\begin{array}{c}\text { Gearbox } \\
\text { efficiency }\end{array}$ & $\begin{array}{c}\text { The } \\
\text { buckets } \\
\text { moving } \\
\text { speed }\end{array}$ & $\begin{array}{c}\text { The wall } \\
\text { gap } \\
\text { parameter } \\
\left(G^{*}\right)\end{array}$ & $\begin{array}{c}\text { The } \\
\text { cylinder } \\
\text { gap } \\
\text { parameter } \\
\left(L^{*}\right)\end{array}$ \\
\hline Base value & $80 \%$ & $10 \%$ & $90 \%$ & $0.65 \mathrm{~m} / \mathrm{s}$ & 0.25 & 1.25 \\
\hline
\end{tabular}

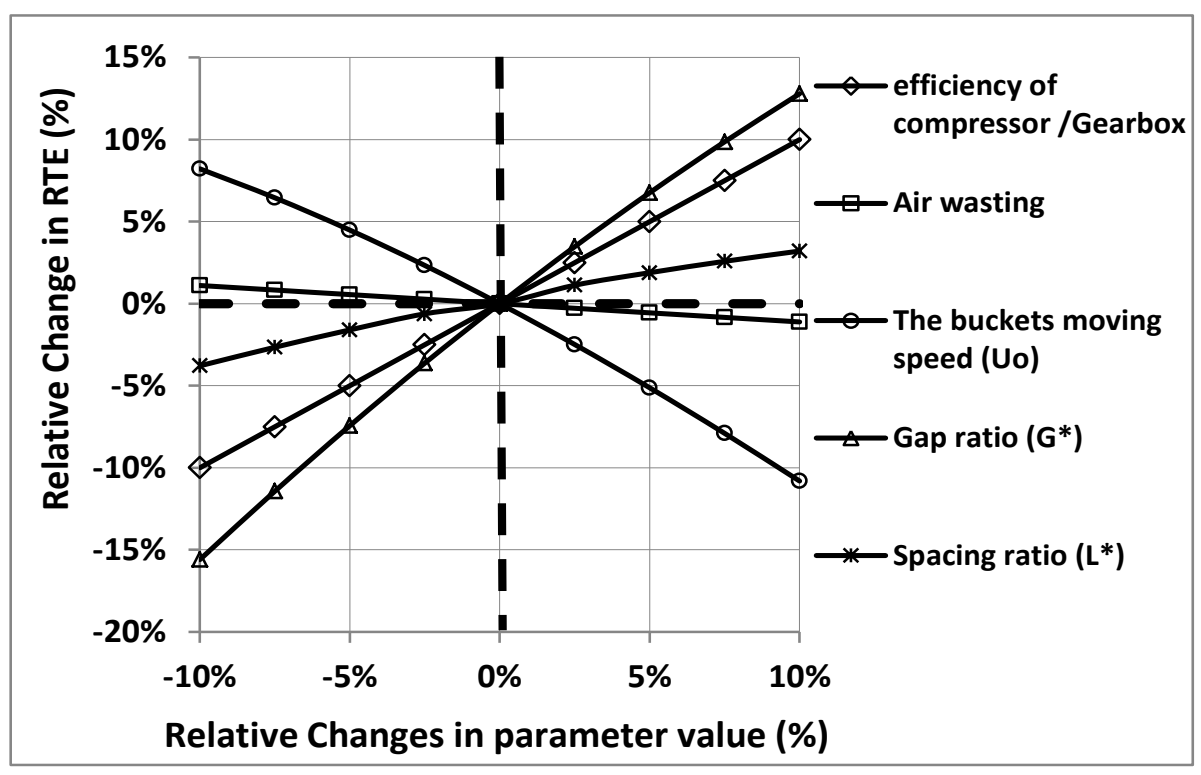

Fig.15 Sensitivity analysis for the round trip efficiency of CAES/BPG system

\section{Conclusions}


This study has introduced a method for coupling the compressed air energy storage (CAES) with buoyancy force energy storage (BPG) for the wind/solar energy storage. Key design parameters of the buoyancy power generation; i.e. $L^{*}, G^{*}$, and $U o$ were investigated to optimize the system performance. The following points have been concluded from the physical and hydraulic assessments of the CAES/BPG system:

- ANSYS-Fluent was applied to simulate the performance of the BPG system and k- $\omega$ SST turbulence model was selected for calculating the required flow parameters.

- $\quad$ Based on the ANSYS-Fluent results, the buckets drag force increased with decreasing $G^{*}$ and increasing $L^{*}$.

- The obtained results showed that the maximum value of net buoyancy power density and the maximum energy density production occurred at $L^{*}=1.25, G^{*}=0.25$ and $U_{o}=0.65 \mathrm{~m} / \mathrm{s}$.

- The results showed also the optimum of the buckets moving speed has an increasing trend by increased $G^{*}$ while the optimum speed is slightly decreased with increasing $L^{*}$.

- The RTE of the proposed BPG system was between $47 \%$ and $60 \%$ for different $G^{*}$ values, indicating its potential as an alternative method to other energy storage technologies, such as Hydro, Flywheels, Batteries, Electro-Thermal (ETES) and Compressed Air (CAES).

- The sensitivity analysis results showed that the gap ratio parameter has the highest effect on the resulting $R T E$ and then the buckets moving speed is the most effective parameter. Inversely, the spacing ratio and air wasting from the buckets have the lowest effects on the resulting $R T E$.

The proposed air-displacement system is a promising method to replace chemical-based processes. This system reduces environmental pollution during the operational time and can entirely be recycled at the end of its life. Future work should focus on building a laboratory size airdisplacement system for power generation, and model validation using experimental data.

\section{Acknowledgments}

This work was supported as part of the first author's sabbatical leave. The authors gratefully acknowledge the University of Technology Sydney and Shahrekord University for their support. It can be noted that the authors are pleased to share their data set with readers who wish to replicate the results of this study.

\section{References}

[1] Mahlia TMI, Saktisahdan TJ, Jannifar A, Hasan MH, Matseelar HSC. A review of available methods and developments on energy storage; technology update. Renew Sustain Energy Rev 2014; 33:532- 
[2] Hemmati R. Optimal design and operation of energy storage systems and generators in the network installed with wind turbines considering practical characteristics of storage units as design variable. Journal of Cleaner Production, 2018, 185, 680-693.

[3] Aneke M, Wang M. Energy storage technologies and real life applications - A state of the art review. Applied Energy 2016; $179: 350-377$.

[4] Zhou, Shu-Wei; Xia, Cai-Chu; Du, Shi-Gui; Zhang, Ping-Yang; Zhou, Yu. An Analytical Solution for Mechanical Responses Induced by Temperature and Air Pressure in a Lined Rock Cavern for Underground Compressed Air Energy Storage, Rock Mechanics and Rock Engineering, 2015, 48, $749-770$

[5] Asmae Berrada, Khalid Loudiyi, Izeddine Zorkani. Dynamic modeling and design considerations for gravity energy storage. Journal of Cleaner Production, 2017; 159: 336-345.

[6] Guo H, Xu Y, Chen H, Zhou X. Thermodynamic characteristics of a novel supercritical compressed air energy storage system. Energy Conversion and Management, 2016; 115: 167-177.

[7] P. Perazzelli, G. Anagnostou. Design issues for compressed air energy storage in sealed underground cavities. Journal of Rock Mechanics and Geotechnical Engineering, 2016; 8: 314-328.

[8] He J, Liu P, Li Z. Dynamic modeling and design of a hybrid compressed air energy storage and wind turbine system for wind power fluctuation reduction, Computers \& Chemical Engineering, Available online 30 May 2018.

[9] Hemmati R. Technical and economic analysis of home energy management system incorporating smallscale wind turbine and battery energy storage system. Journal of Cleaner Production, 2017; 159: 106118.

[10] Ramadan O, Omer S, Ding Y, Jarimi H, Chen X, Riffat S., Economic evaluation of installation of standalone wind farm and Wind+CAES system for the new regulating tariffs for renewables in Egypt. Thermal Science and Engineering Progress, Available online 15 June 2018, doi.org/10.1016/j.tsep.2018.06.005.

[11] Alami AH. Experimental assessment of compressed air energy storage (CAES) system and buoyancy work energy storage (BWES) as cellular wind energy storage options. J of Energy Storage 2015; 1: $38-43$.

[12] Bassett KP, Carriveau R, Ting D. Integration of buoyancy-based energy storage with utility scale wind energy generation. J of Energy Storage 2017; 14- Part 2: 256-263.

[13] Alami A H. Analytical and experimental evaluation of energy storage using work of buoyancy force. $\mathrm{J}$ of Renewable and Sustainable Energy reviews, 2014; 6: 013137.

[14] ThornbrueT, Ghorbani R. An introduction to large scale buoyant energy storage technology. In OCEANS 2010 Conference.

[15] https://infinitysav.com/

[16] Diamond D. Gravity-actuated fluid displacement power generator. U.S. Patent 3934 964, Jan. 27, 1976. 
[17] Radzevich S.P. Dudley's Handbook of Practical Gear Design and Manufacture, Second Edition. CRC Press, 2012; 878 pages.

[18] Bell WH. The influence of turbulence on drag. Ocean Engng 1979; 6: 329-340.

[19] Wang XK, Zhang JX, Hao Z, Zhou B, Tan SK. Influence of wall proximity on flow around two tandem circular cylinders. Ocean Engineering 2015; 94:36-50.

[20] ANSYS FLUENT 12.1 Theory Guide; 2010.

[21] Aftab SMA, Mohd Rafie AS, Razak NA, Ahmad KA. Turbulence model selection for low Reynolds number flows. PLOS ONE 2016; 11(4): e0153755.

[22] Ladjedel O, Adjlout L, Imine O, Yahiaoui T, Aounalah M. Experimental and numerical studies of turbulent flow in an in-line tube bundles. EPJ Web of Conferences published by EDP Sciences; 2012; $25,01044$.

[23] Menter F. R. Two-equation eddy-viscosity turbulence models for engineering applications, AIAA journal, 1994; 32 (8): 1598-1605.

[24] SAS IP, Inc.ANSYS Fluent Theory Guide2013.

[25] Patel Y, Numerical investigation of flow past a circular cylinder and in a staggered tube bundle using various turbulence models. Master's thesis, Lappeenranta University of Technology; 2010: 87.

[26] Young ME, Ooi A. Turbulence models and boundary conditions for Bluff body flow. Proceeding of 15th Australasian Fluid Mechanics Conference; 2004.

[27] Coughtrie AR, Borman DJ, Sleigh PA. Effects of turbulence modeling on prediction of flow characteristics in a bench-scale anaerobic gas-lift digester. Bioresource Technology 2013; 138:297306.

[28] Ducrocq T, Cassan L,Chorda J,Roux H. Flow and drag force around a free surface piercing cylinder for environmental applications. Environmental Fluid Mechanics. 2017; 17: 629-645.

[29] Rahimzadeh H, Maghsoodi R, Sarkardeh H, Tavakkol S. Simulating flow over circular spillways by using different turbulence models. Engineering Applications of Computational Fluid Mechanics. 2012; 6 (1): 100-109.

[30] Dogan S, Yagmur S, Goktepeli I, Ozgoren M. Assessment of turbulence models for flow around a surface-mounted cube. International Journal of Mechanical Engineering and Robotics Research. 2017 ; 6 (3): 237-241.

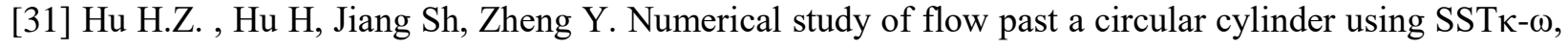
LES and ELES formulations. Progress in Computational Fluid Dynamics, an International Journal. 2015; 15: 203-213.

[32] Benton N, Burns P. Compressed air evaluation protocol, the uniform methods project: methods for determining energy-efficiency savings for specific measures, Chapter 22. Golden, CO; National Renewable Energy Laboratory. NREL/SR-7A40-68577; 2017.

[33] ASME PTC-10, Performance test code on compressors and exhausters. 1997. 
1 [34] Campbell J.M. Gas conditioning and processing, Volume 2: The Equipment Modules, 9th Edition, 2 2nd Printing, Petroleum Series, Norman, Oklahoma, 2014.

3 [35] Øvergaard S. Issue paper: definition of primary and secondary energy. In: Standard International 4 Energy Classification (SIEC) in the International Recommendation on Energy Statistics (IRES). Oslo $5 \quad$ Group on Energy Statistics 2008:1-7.

6 [36] Florin N, Dominish E. Sustainability evaluation of energy storage technologies. Report prepared by the Institute of Sustainable Futures for the Australian Council of Learned Academies, University of Technology Sydney; 2017.

9 [37] Akhil AA, Huff G, Currier AB, Kaun BC, Rastler DM. Electricity Storage Handbook. Sandia National 10 Laboratories, Albuquerque NM; 2013.

11 [38] Sobol IM. Global sensitivity indices for nonlinear mathematical models and their Monte Carlo 12 estimates. Math Comput Simul. 2001; 55: 271-80. 